\title{
MCrAlY/TaC Metal Matrix Composite Coatings Produced by Electrospark Deposition
}

\author{
Yujiang XIE ${ }^{1 \dagger \dagger}$, Yanhong YANG ${ }^{1)}$, Mingsheng $W A N G^{1)}$ and Jian $H O U^{2)}$
}

1) State Key Laboratory for Corrosion and Protection, Institute of Metal Research, Chinese Academy of Sciences, Shenyang 110016, China

2) Shenyang Liaohai Equipment Co., Ltd., Shenyang 110003, China

[Manuscript received 6 December 2012, in revised form 10 January 2013]

(C) The Chinese Society for Metals and Springer-Verlag Berlin Heidelberg

\begin{abstract}
$M \mathrm{CrAlY} / \mathrm{TaC}$ metal matrix composite coatings with 10,20 and $30 \mathrm{wt} . \% \mathrm{TaC}$ have been successfully produced by electrospark deposition (ESD). The effects of $\mathrm{TaC}$ content on microstructure, hardness and oxidation behavior of the composite coatings were studied. The results showed that the composite coatings were composed of superfine $\gamma$ columnar dendrite and large $\mathrm{TaC}$ particles dispersedly distributed. The hardness was enhanced but oxidation resistance of the composite coatings was reduced with increasing $\mathrm{TaC}$ contents.
\end{abstract}

KEY WORDS: MCrAlY; Metal matrix composite; Coating; Electrospark deposition

\section{Introduction}

Turbine blade experiences harsh conditions, often suffered from oxidation and wear at its tip. To meet these new challenges and operate the turbine components at much higher temperature, metal-matrix composite (MMC) coatings are being considered to obtain better wear- and oxidation-resistant properties. These coatings may be developed by adding wear-resistant ceramic particles (such as $\mathrm{Al}_{2} \mathrm{O}_{3}$, HfC and $\mathrm{SiC}$, etc.) into the oxidation-resistant $M \mathrm{CrAlY}$ matrix ${ }^{[1]}$. The composite coatings have been prepared by laser cladding or thermal spraying ${ }^{[2,3]}$. In the laser cladding process, a strong metallurgical bond can be obtained, but often in the risk of thermal damage to blade substrate due to its high susceptibility to hot cracking. In the thermal spraying process, no thermal damage is caused, but the composite coating weakly adheres to the substrate. In contrast, it is possible to produce a metallurgical bonded coating in virtue of minimum thermal damage to substrate materials by using electrospark

\footnotetext{
† Corresponding author. Assoc. Prof., Ph.D.; +86 24 23915863; Fax: +86 2423890049 ; E-mail address: yjxie@imr.ac.cn (Yujiang XIE)
}

DOI: $10.1007 / \mathrm{s} 40195-012-0236-8$ deposition process ${ }^{[4]}$.

Electrospark deposition is a very versatile process and different kinds of coatings have been produced by this process ${ }^{[5-9]}$. However, to the best knowledge of the authors, MMC coatings are seldom been reported so far. Our previous work has attempted to prepare a wear- and oxidation-resistant MMC coating by electrospark deposition of $M \mathrm{CrAlY} / \mathrm{BN}^{[10]}$. However, it failed due to the decomposition of $\mathrm{BN}$. TaC has a high melting point of $3880{ }^{\circ} \mathrm{C}$ and excellent properties such as high hardness and high resistance to chemical reagents. Even at higher temperature, its hardness is not lower than that of diamond. TaC particles reinforced $\mathrm{NiCrBSi}$ composite coating has been successfully produced by laser cladding ${ }^{[11]}$. The current work shows the feasibility to obtain $M \mathrm{CrAlY} / \mathrm{TaC}$ MMC coating by electrospark deposition and investigates the effects of $\mathrm{TaC}$ content on microstructure, hardness and oxidation resistance of the composite coatings. It is expected that the preliminary results can be beneficial to the development of wear- and oxidation-resistant composite coatings.

\section{Experimental Details}

A 3H-ES-6 ESD machine with a rapidly rotating electrode, high spark energy and high frequency, was 
used to prepare the coatings. The deposition was carried out under the condition of $540 \mathrm{~W}$ and $300 \mathrm{~Hz}$. During deposition the electrode was oriented preferentially at an angle of $30^{\circ}-45^{\circ}$ to the work-piece and rotated at a speed of $3000 \mathrm{r} / \mathrm{min}$, the shielding argon gas was delivered through a side cover and flowed at a rate of $25 \mathrm{~mL} / \mathrm{min}$. The revolving electrode was in traveling contact with the work-piece surface and the electrode material was transferred through the arc of every miniature lightning strike. With a succession of pulsed spark discharge deposition, the coating with a desirable thickness was obtained.

A Ni-base superalloy with the composition (wt.\%) of Ni-11.5Cr-8.5Co-3.3Al-3.35Ti-1.85Mo-3.7W-3.9Ta$0.05 \mathrm{Zr}$, was cut into the specimens with dimensions of $10 \mathrm{~mm} \times 15 \mathrm{~mm} \times 2 \mathrm{~mm}$ as the substrate material. The surface was ground to 600 grit $\mathrm{SiC}$, cleaned ultrasonically in alcohol, and then blown dry. The composites of $M \mathrm{CrAlY}$ powder with addition of 10, 20 and 30 wt. $\%$ TaC were used to make the electrode materials. The $M \mathrm{CrAlY}$ powder had a composition (wt.\%) of Ni-23Co-20Cr-8Al-4Ta-0.6Y. The electrode materials used for ESD were formed by laser casting wire techniques. The microstructure of the composite electrode materials with 10, 20 and 30 wt.\% TaC are shown in Fig. 1. As it is shown in Fig. 1, with an increasing addition of $\mathrm{TaC}$, the amount of $\mathrm{TaC}$ (white particles) in the composite obviously increased.

The phase compositions of the composite coatings were identified by means of X-ray diffractometry (XRD). The microstructural morphologies were observed by scanning electron microscopy (SEM). The hardness distribution of the coatings was investigated by microhardness tester. Isothermal oxidation tests were carried out in ambient air in a muffle furnace at $1000{ }^{\circ} \mathrm{C}$ for $100 \mathrm{~h}$.

\section{Results and Discussion}

Fig. 2 shows the XRD patterns of $M \mathrm{CrAlY} / \mathrm{TaC}$ composite coatings with 10, 20 and 30 wt.\% TaC, respectively. It can be clearly seen that the more strong $\mathrm{TaC}$ peaks can be identified in the composite coatings with the increase of $\mathrm{TaC}$ contents and the final products of the three composite coatings contain both $\mathrm{TaC}$ and $\gamma$.

Fig. 3 shows the cross-sectional morphologies of
$M \mathrm{CrAlY} / \mathrm{TaC}$ composite coatings with 10, 20 and 30 wt.\% TaC, respectively. The composite coatings are fully dense, and there are no cracks to be observed between the coating layer and the substate. The white particles visible in the composite coatings are $\mathrm{TaC}$ phase. The amount of $\mathrm{TaC}$ particles in the coatings increased with increasing $\mathrm{TaC}$ content in the electrode materials. Between the coatings and substrate, there are clearly visible fusion layers as shown in Fig.4, indicating that the coatings strongly bonded with the substrate.

Fig. 5 shows microstructure morphologies of $M \mathrm{CrAlY} / \mathrm{TaC}$ composite coatings with 10, 20 and 30 wt.\% TaC respectively. It's very interesting to notice that all of the composite coatings were composed of superfine $\gamma$ columnar dendrite and large TaC particles dispersedly distributed. Furthermore, the presence and increase of $\mathrm{TaC}$ particles didn't effect the directionally solidified structure of the composite coatings. The shape of $\mathrm{TaC}$ particles was not spherical, and the size of $\mathrm{TaC}$ particles is close to that in electrode materials. The results suggest that $\mathrm{TaC}$ particles in the electrode were not melted or fully melted and were directly transferred to substrate with molten $M$ CrAlY from electrode during electrospark deposition. It was quite different from previous reports ${ }^{[12,13]}$ on electrospark coatings containing ceramic particles such as $\mathrm{TiC}$ and $\mathrm{Y}_{2} \mathrm{O}_{3}$, in which the ceramic particles would melt and solidify preferentially as nuclei after melting and

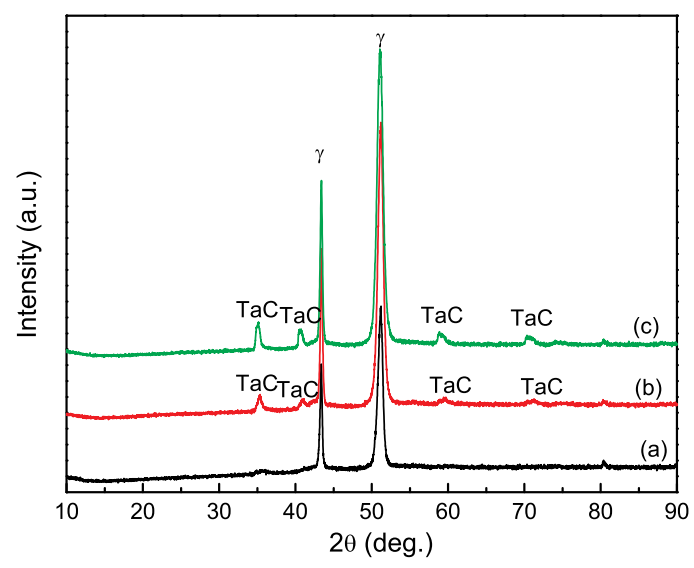

Fig. 2 XRD patterns of $M \mathrm{CrAlY} / \mathrm{TaC}$ composite coatings with 10 wt.\% (a), 20 wt.\% (b) and 30 wt.\% (c) $\mathrm{TaC}$

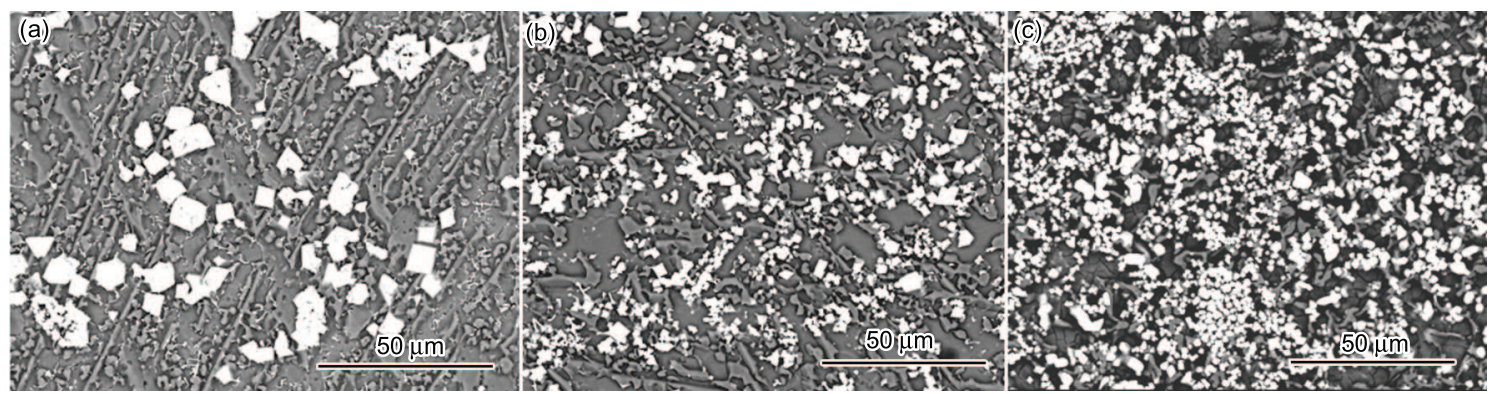

Fig. 1 Microstructure of the $M \mathrm{CrAlY} / \mathrm{TaC}$ composite rods with 10 wt.\% (a), 20 wt.\% (b) and 30 wt.\% (c) $\mathrm{TaC}$ 


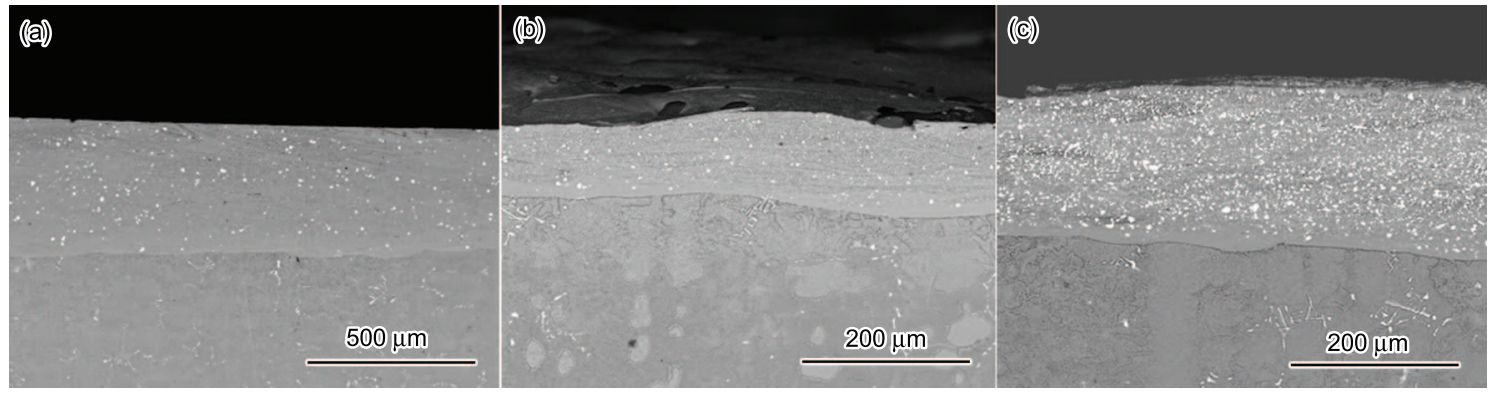

Fig. 3 Cross-sectional morphologies of $M \mathrm{CrAlY} / \mathrm{TaC}$ composite coatings with 10 wt.\% (a), 20 wt.\% (b) and 30 wt.\% (c) $\mathrm{TaC}$

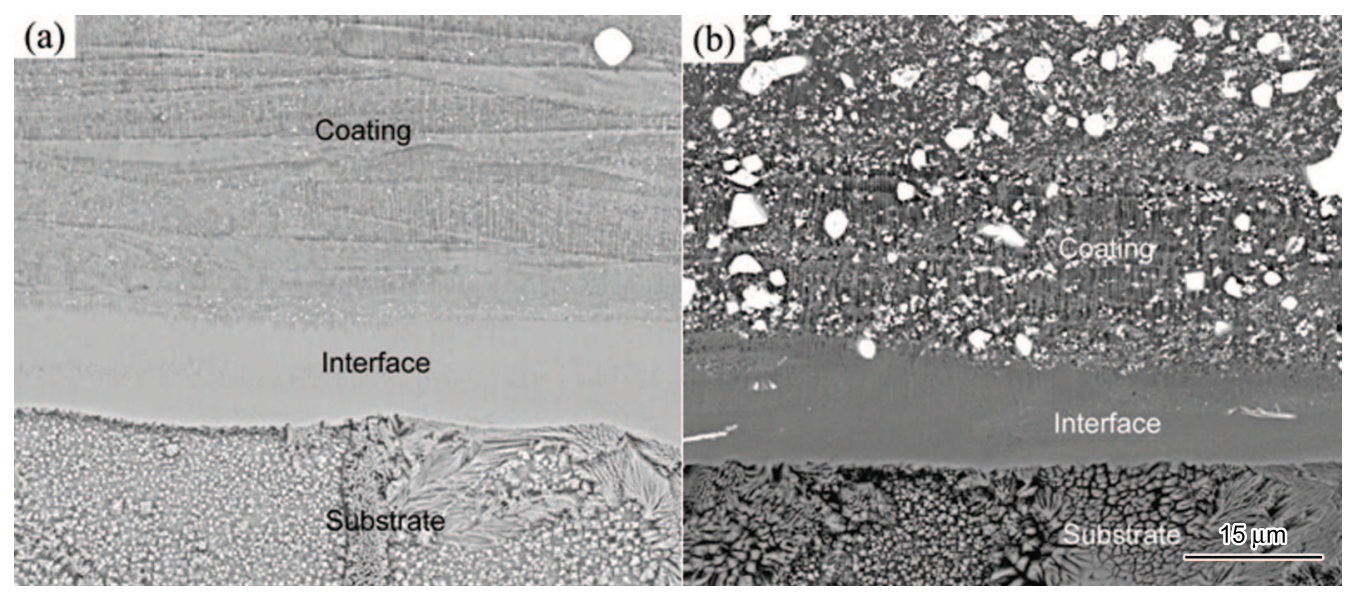

Fig. 4 Interface morphologies of $M \mathrm{CrAlY} / \mathrm{TaC}$ composite coatings with 10 wt.\% (a) and 30 wt.\% (b) TaC
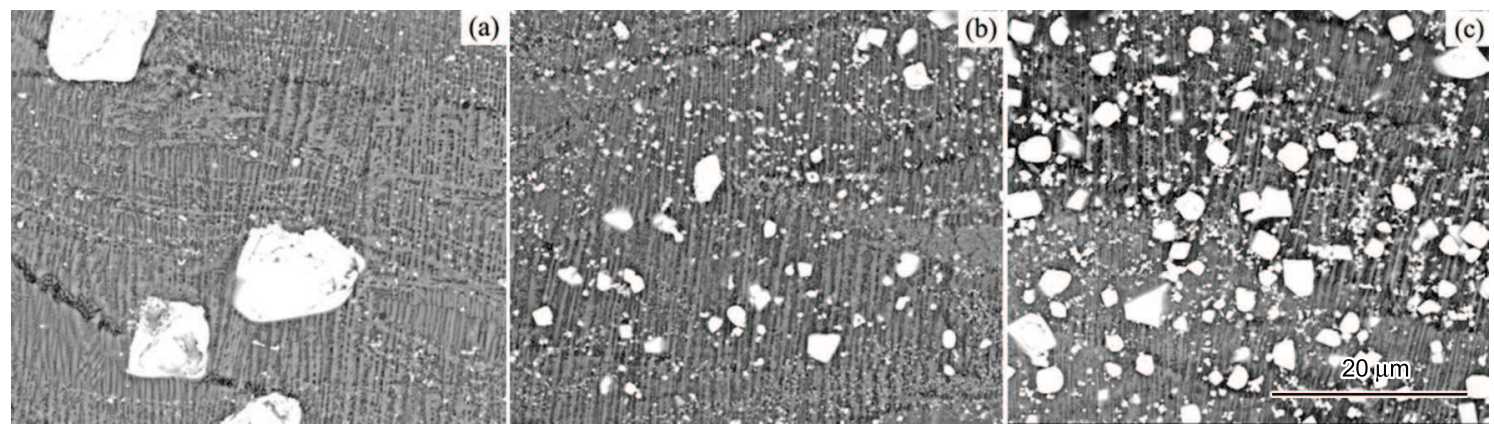

Fig. 5 Microstructure morphologies of $M \mathrm{CrAlY} / \mathrm{TaC}$ composite coatings with 10 wt.\% (a), 20 wt.\% (b) and 30 wt.\% (c) TaC

solidification of electrode. This could be mainly attributed to higher melting point for TaC.

Fig. 6 shows the microhardness profiles of $M \mathrm{CrAlY} / \mathrm{TaC}$ composite coatings with 10, 20 and 30 wt.\% TaC. The microhardnesses of the coating and the substrate are shown on the left and right sides, respectively. The curves (a), (b) and (c) indicated that the hardnesses of the composite coatings gradually increased with increasing $\mathrm{TaC}$ content. The average hardness of the composite coating with the least $\mathrm{TaC}$ addition was about $530 \mathrm{HV}_{0.1}$. The hardness would increase to $640 \mathrm{HV}_{0.1}$ when the TaC content reached to 30 wt.\%.

Fig. 7 shows oxidation kinetics of $M \mathrm{CrAlY} / \mathrm{TaC}$ composite coatings with 10, 20 and 30 wt.\% TaC at $1000^{\circ} \mathrm{C}$ for $100 \mathrm{~h}$. The curves were characterized by steeply increasing at initial stage and then leveling off regardless of the TaC content in the deposited coating. In addition, it could be seen that the coating with higher TaC content had a greater mass gain. The oxidation behavior of the coating with $30 \mathrm{wt} . \% \mathrm{TaC}$ was far inferior to those of other two coatings, and after exposed at $1000^{\circ} \mathrm{C}$ for $100 \mathrm{~h}$ its weight gain was more than twice those of the others. The results indicated that the oxidation resistance of $M \mathrm{CrAlY} / \mathrm{TaC}$ composite coatings was obviously reduced with increasing TaC contents.

Fig. 8 shows the cross-section morphologies of oxidized $M \mathrm{CrAlY} / \mathrm{TaC}$ composite coatings prepared by ESD with 10, 20 and 30 wt.\% TaC when exposed at $1000{ }^{\circ} \mathrm{C}$ for $100 \mathrm{~h}$. For the composite coating with 10 wt. $\%$ TaC addtion, a continuous but less adherent layer assumed to $\alpha-\mathrm{Al}_{2} \mathrm{O}_{3}$ was formed. When it comes to the other two composite coatings, discontinous 


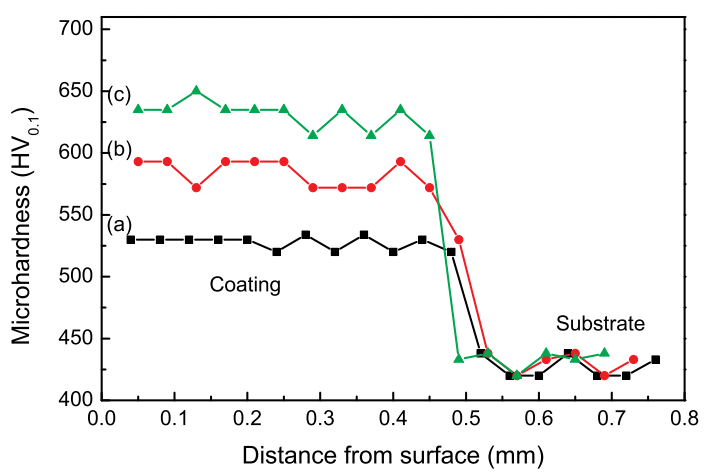

Fig. 6 Microhardness profiles of $M \mathrm{CrAlY} / \mathrm{TaC}$ composite coatings with 10 wt.\% (a), 20 wt.\% (b) and 30 wt.\% (c) $\mathrm{TaC}$

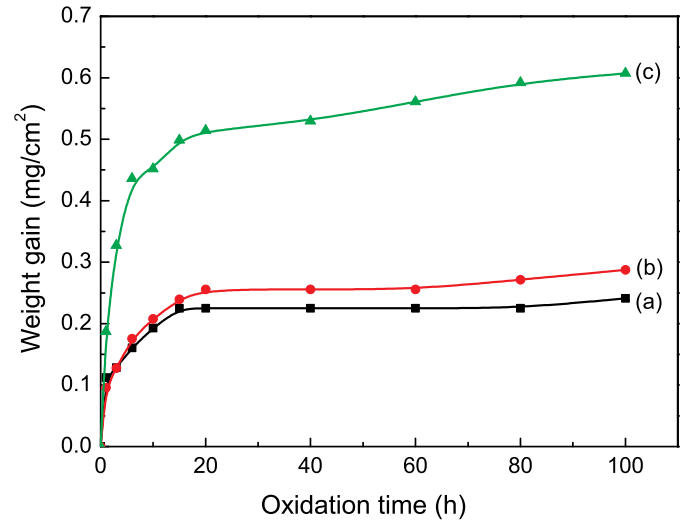

Fig. 7 Oxidation kinetics curves of $M \mathrm{CrAlY} / \mathrm{TaC}$ composite coatings with $10 \mathrm{wt} . \%$ (a), $20 \mathrm{wt} . \%$ (b) and 30 wt.\% (c) $\mathrm{TaC}$ when exposed at $1000{ }^{\circ} \mathrm{C}$ for $100 \mathrm{~h}$
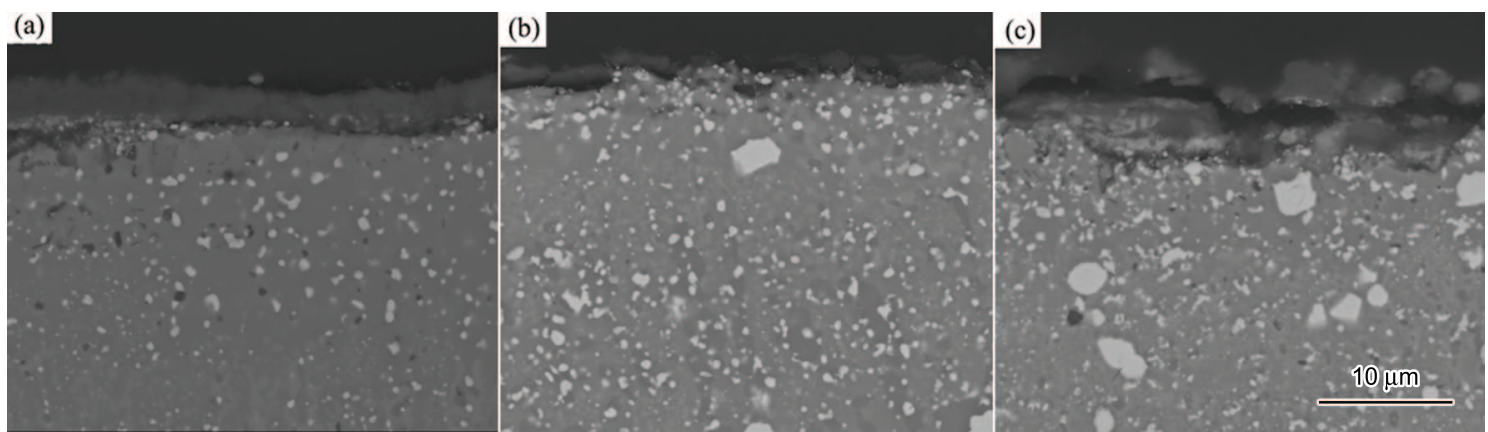

Fig. 8 Cross-section of oxidized $M \mathrm{CrAlY} / \mathrm{TaC}$ composite coatings with 10 wt.\% (a), 20 wt.\% (b) and 30 wt.\% (c) TaC when exposed at $1000{ }^{\circ} \mathrm{C}$ for $100 \mathrm{~h}$

oxide scales were formed. It can be clearly seen that the oxidation-resistance of the composite coatings dramatically deteriorated with increasing $\mathrm{TaC}$ content. It is well known that $\mathrm{TaC}$ begins to be oxidized into $\mathrm{Ta}_{2} \mathrm{O}_{3}$ over $500{ }^{\circ} \mathrm{C}$, then form porous $\mathrm{Ta}_{2} \mathrm{O}_{5}$ particles over $700{ }^{\circ} \mathrm{C}^{[14]}$. The increasing amount of $\mathrm{Ta}_{2} \mathrm{O}_{5}$ in the oxide scale will be harmful for the formation of a dense and continuous alumina layer, which may be the main reason for reduced oxidation resistance of the composite coatings.

\section{Conclusion}

$M \mathrm{CrAlY} / \mathrm{TaC}$ composite coatings can be successfully produced by electrospark deposition. The composite coatings consisted of superfine $\gamma$ columnar dendrite matrix and large dispersedly distributed $\mathrm{TaC}$ particles. The existence and increase of $\mathrm{TaC}$ particles didn't effect the directionally solidified structure of the composite coatings. The hardness was enhanced but oxidation resistance of the composite coatings was reduced with increasing $\mathrm{TaC}$ content.

\section{Acknowledgement}

The work was supported by the National Natural Science Foundation of China (No.50901081).

\section{REFERENCES}

[1] M. Ohara and M. Mega, US Patent, No.6811898, 2004.

[2] D. Wolfe and J. Singh, J. Mater. Sci. 33 (1998) 3677.

[3] L.D Zhao, M. Parco and E. Lugscheider, Surf. Coat. Technol. 184 (2004) 298.

[4] Y.J. Xie, M.C. Wang and D.W. Huang, Appl. Surf. Sci. 253 (2007) 6149.

[5] R.J. Wang, Y.Y. Qian and J. Liu, Appl. Surf. Sci. 240 (2005) 42.

[6] Y.J. Xie and M.C. Wang, Surf. Coat. Technol. 201 (2006) 3564.

[7] S. Cadney and M. Brochu, Intermetallics 16 (2008) 518.

[8] Z.J. Feng and C.L. Zeng, J. Power Sources 195 (2010) 4242.

[9] B. Zhang, L. Ma, Z.J. Liang and J.J. Zhao, Acta Metall. Sin. (Eng. Lett.) 24 (2011) 309.

[10] Y.J. Xie, M.C Wang, J. Alloys Compd. 484 (2009) 21.

[11] M.J. Chao, W.L. Wang, E.J. Liang and D.X. Ouyang, Surf. Coat. Technol. 202 (2008) 1918.

[12] Y. He, H. Pang, H. Qi, D. Wang, Z. Li and W. Gao, Mater. Sci. Eng. A 334 (2002) 179.

[13] S.K. Tang, T.C. Nguyen and Y. Zhou, Weld J. 89 (2010) 172.

[14] G.D. Li, X. Xiong and K.L. Huang, Trans. Nonferrous Met. Soc. China 19 (2009) S689. 